\title{
LA PLUSVALÍA COMO CONTRIBUCIÓN ESPECIAL CON FINES URBANÍSTICOS'
}

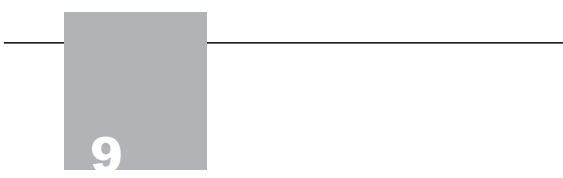

\section{Sumario:}

\begin{abstract}
Introducción. Anotaciones preliminares. Aumentos en el valor de la tierra urbana o fundamentos económicos de los instrumentos de recuperación de plusvalías. Fundamentos dogmáticos de los instrumentos de recuperación de plusvalías. Fundamentos en la LDT. Naturaleza jurídica de la plusvalía. Definición. El hecho imponible. Aspecto material. Aspecto espacial. Aspecto cuantitativo. Aspecto temporal.
\end{abstract}

\section{Nidia María Barreto CruZ²}

\section{Introducción}

Como desarrollo de los principios de la función social de la propiedad y de la prevalencia del interés general sobre el particular, el constituyente de 1991 consideró justo y equitativo que la sociedad participara de los beneficios y aumentos en las rentas de la tierra, originados en la normativa urbanística y en la disponibilidad de infraestructura. Fue así como se dispuso en el artículo 82 de la Carta Política que las entidades públicas participarán en la plusvalía que genere su acción urbanística, disposición que desarrollaría años más tarde mediante los artículos 73 a 90 de la Ley de Desarrollo Territorial (388 de 1997, en adelante LDT). A la fecha, la plusvalía se ha configurado como un instrumento de gestión de los planes de ordenamiento territorial de los municipios, distritos y áreas metropolitanas, ligado al desarrollo urbano y que destina principalmente los recursos que genera a la construcción de vivienda de interés social y a la provisión de obras públicas. No obstante, con frecuencia se discute acerca de su naturaleza jurídica, centrándose la discusión en si se puede considerar un recurso tributario o, por el contrario, una nueva categoría de ingreso público. $\mathrm{Al}$ respecto, el propósito del presente artículo es demostrar que se trata de un gravamen de carácter municipal,
1. Este documento es la síntesis de una investigación más amplia denominada La participación en plusvalías como contribución especial con fines urbanísticos, realizada por la autora y el Centro de Estudios Fiscales de la Universidad Externado de Colombia durante 2001.

2. Abogada de la Universidad Externado de Colombia. Investigadora del Centro de Estudios Fiscales. 
distrital y metropolitano, que tiene por hecho generador las acciones urbanísticas relacionadas con la reglamentación de usos y densidades del suelo.

\section{Anotaciones preliminares}

En la historia fiscal colombiana se pueden reconocer como antecedentes de "instrumentos de recuperación de plusvalías" la contribución de valorización y la contribución por desarrollo municipal. La primera goza de gran reconocimiento en América Latina (bajo la denominación común de contribución de mejoras), y en el caso colombiano se estableció desde 1921 como un tributo destinado a la financiación de obras públicas. En la actualidad se encuentra caracterizada por la Ley 48 de 1968 como una contribución limitada al costo de la inversión realizada por la Nación, los departamentos, los municipios, el Distrito Especial de Bogotá o cualquier otra entidad de derecho público que realice obras que proporcionen beneficios a la propiedad inmueble, sin perjuicio que se cobre un porcentaje adicional establecido por la ley para imprevistos y gastos de funcionamiento.

La segunda, por su parte, fue creada por la Ley 9. ${ }^{\text {a de }} 1989$ o Ley de Reforma Urbana, como un mecanismo de recuperación para la sociedad de la plusvalía generada sobre el suelo urbano por el proceso de crecimiento de las ciudades, para permitirle al Estado la ejecución de planes de vivienda orientados a atender las necesidades de las clases menos favorecidas. Se trataba de un tributo nacional con destinación específica que se liquidaba sobre el mayor valor que adquirían los predios producto de la normativa urbanística. A pesar de los propósitos que la inspiraban, esta figura tuvo problemas operativos debido a la desactualización de los catastros municipales y devino inconstitucional en 1991 en virtud de que el artículo 317 superior dispuso que solamente los municipios podrán gravar la propiedad inmueble.

\subsection{Aumentos en el valor de la tierra urbana o fundamentos económicos de los instrumentos de recuperación de plusvalías}

En un sentido amplio, los instrumentos de recuperación de plusvalías son herramientas tributarias o no tributarias que 
emplean los Estados para captar los incrementos en el "valor de la tierra urbana", originados en el esfuerzo de la sociedad. En este sentido resulta pertinente definir el concepto de "renta de la tierra urbana", por oposición a la "renta de la tierra rural", para abordar posteriormente el estudio de los fines de los instrumentos de captura, y la estructura jurídica de la plusvalía. Frente a esta cuestión nos remitiremos a los planteamientos del economista SAMUEL JARAMILLO, quien ha estudiado y analizado ampliamente la "teoría de la renta de la tierra"

Explica el autor que la propiedad inmobiliaria urbana genera unas rentas que surgen de los sobreprecios que los consumidores de edificaciones están dispuestos a pagar por ellas a los constructores, en virtud de su localización en determinados terrenos, por lo cual la razón que le da sentido a su existencia social es la capacidad que tiene de soportar espacio urbano (soportar "actividades urbanas") en contraste con la tierra rural que sostiene el ciclo vegetal. A los sobreprecios se les llama rentas generadas con motivo del proceso de producción (de construcción y cultivos).

Se diferencia entonces la tierra urbana de la rural en que su producto, esto es, el espacio construido, permanece atado a ella en el proceso de consumo, mientras que en la rural sólo hay rentas ligadas al proceso de producción, por lo cual en lo urbano se presentan rentas de producción y de consumo. Además, las rentas urbanas de consumo son atractivas porque experimentan considerables aumentos. No obstante, la estructura de estas rentas no es fija, sino que, por el contrario, lo común en una ciudad es que los precios de los terrenos cambian constantemente y con "movimientos" de diversos tipos.

Los movimientos denominados estructurales particulares son los más destacados en el proceso de consumo de las rentas urbanas, sin perjuicio de las otras clases de movimientos, y se encuentran asociados a dos fenómenos que son: (i) los cambios de uso del suelo, y (ii) los cambios en las densidades. Es de anotar que estos dos fenómenos pueden ser propiciados por el mercado o por el Estado mediante reglamentación de los usos y densidades y la realización de obras públicas.

En resumidas cuentas, los "incrementos de valor de la tierra" son aquellas valorizaciones experimentadas por determinados terrenos en diversas etapas del proceso de urbanización, en tanto que la noción de "plusvalías" hace referencia a los

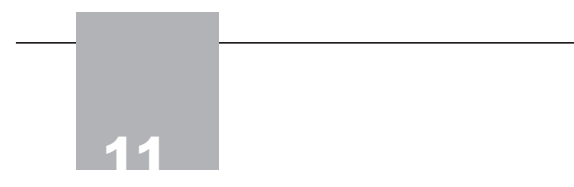

3. Samuel Jaramillo. Hacia una teoría de la renta del suelo urbano, Bogotá, Universidad de los Andes-Instituto Geográfico Agustín Codazzi, 1994. 
incrementos del valor de la tierra derivados de la actuación pública, bien sea a través de inversiones en infraestructura o de decisiones reglamentarias sobre el uso del suelo. Y la "recuperación de plusvalías" consiste en la movilización de parte de aquellos incrementos del valor de la tierra atribuible a esfuerzos de la comunidad para convertirlos en ingresos públicos mediante tributos, concesiones, "comercialización o participación de terrenos u otras cobranzas, o más directamente en mejoramientos in loco en beneficio de los ocupantes o de la comunidad en general"4.

\subsection{Fundamentos dogmáticos de los instrumentos de recuperación de plusvalías}

Los diferentes mecanismos de recuperación de plusvalías encuentran en las legislaciones latinoamericanas diversas justificaciones que los hacen viables. En primera instancia, las constituciones de la región le atribuyen a la propiedad privada una función social que permite limitar el apreciado

4. AA. vv. Recuperación de plusvalías en América Latina: alternativas para el desarrollo urbano, Cambridge, Lincoln Institute Of Land PolicyPontificia Universidad Católica de Chile, Edit. Eurelibros, 2001, XVI.

5. Mario Lungo. "Expansión urbana y regulación del uso del suelo en América Latina", en Landlines: [www.lincolninst.edu] derecho de propiedad por razones de interés público, como son el urbanismo, la salubridad o la educación, bajo la idea de que el interés privado debe ceder al público. En segundo lugar, a partir del principio general del derecho del enriquecimiento ilegítimo que condena el incremento del patrimonio de un sujeto a expensas de otro sin que haya una causa que lo justifique, se admite que la sociedad reclame para sí misma los incrementos de valor que se originan en reglamentaciones estatales y que son ajenos a la acción de los agentes privados.

En Colombia, además de los anteriores fundamentos jurídicos, se han enunciado en la LDT otros principios que autorizan la participación en plusvalías generadas por la acción urbanística, como son la función pública del urbanismo y la distribución equitativa de las cargas y beneficios.

Con base en estos criterios económicos, normas constitucionales y principios del ordenamiento urbano, las distintas legislaciones prevén múltiples mecanismos de recuperación de aumentos en el valor de la tierra con móviles de diversa índole. Así, frente a un panorama de pobreza, informalidad e ilegalidad de los patrones de uso del suelo, y ante la ausencia de infraestructura en servicios básicos ${ }^{5}$, se evidencian en Latinoamérica una serie de iniciativas específicas encaminadas 
a la utilización de instrumentos impositivos y paraimpositivos con fines no sólo recaudatorios sino que también propendan por la corrección de las inequidades existentes en la forma de apropiación de las rentas de la tierra originadas en el esfuerzo social.

La recuperación para la colectividad de los "mayores valores" que adquieren los terrenos en razón de obras públicas y de cambios en la reglamentación del uso del suelo y densidades es la cuestión común a estas herramientas. Las operaciones interligadas brasileñas; las contribuciones de mejoras, típicas de la mayoría de los países latinoamericanos; las concesiones urbanas de Chile, y la participación en plusvalías de nuestro país, son reconocidas legítimamente como mecanismos de captura por el sector público de los incrementos de valor en la renta de los predios con loables fines redistributivos ${ }^{6}$.

En el urbanismo moderno, a estas herramientas de captura de aumentos de valor en las tierras se les asignan funciones de planificación y redistribución, siendo mecanismos reguladores del mercado y fuentes de ingresos de los fiscos locales. Tal es el caso de la plusvalía colombiana estructurada como un recurso redistributivo de financiación y de gestión en la planeación y desarrollo de los municipios y distritos.

\subsection{La plusvalía en la LDT}

Desde la expedición de la LDT, la normativa en materia de urbanismo en nuestro país denota importantes cambios en lo concerniente a principios orientadores, metodologías e instrumentos prácticos de gestión urbana. Con esto la plusvalía se constituye en un recurso tributario importante para la financiación del desarrollo municipal a través de los planes de ordenamiento territorial, siempre que en su ejecución se respete la "dogmática urbana" y las potestades tributarias de los entes locales.

El propósito de la LDT, que en su capítulo IX consagró la estructura jurídica de la plusvalía, fue dotar a las administraciones locales de una base normativa que complementara a la Ley 9. a de 1989 o Ley de Reforma Urbana, para adoptar herramientas de planificación y gestión dirigidas a una eficiente organización del territorio municipal. Si bien los objetivos y principios de la Ley de Reforma Urbana se mantienen en la

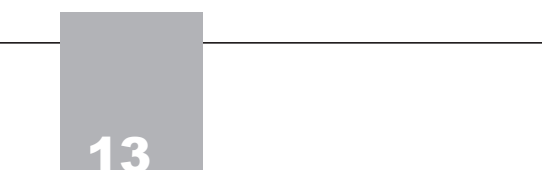

6. En lo relativo a instrumentos de recuperación de plusvalías urbanas en la práctica de América Latina es interesante el trabajo publicado por el Lincoln Institute of Land Policy que agrupa ensayos de diversos autores de la región. Al respecto, consultar: AA. vv. Recuperación de plusvalías en América Latina: alternativas para el desarrollo urbano, Cambridge, Lincoln Institute Of Land PolicyPontificia Universidad Católica de Chile, Edit. Eurelibros, 2001. 
estructura de la LDT, fueron modificadas algunas figuras como la de "desarrollo y construcción prioritaria", cuyos efectos fueron cambiados, y la contribución de desarrollo municipal se reorientó como plusvalía para ajustarla al nuevo texto constitucional.

Así mismo, la LDT busca ajustar la planeación urbana a la noción de planes de desarrollo introducida por la Constitución Política, y a la Ley Orgánica de Planeación, al tiempo que se atendía la realidad de la situación urbana del país definida por la política urbanística de colombia: Ciudades y Ciudadanía, en la que nuestro país se reconoce como un territorio esencialmente urbano, con carencias y desequilibrios en cuanto oportunidades de los ciudadanos para acceder a los beneficios de la urbanización, con un gasto público ineficiente por inadecuada planificación y con ciudades "inacabadas".

El artículo segundo de la LDT se ocupó de consagrar los principios del ordenamiento territorial, que son de gran importancia en la medida en que la aplicación de éstos se

7. Se sustituyó la figura de la extinción del dominio a favor de los municipios de terrenos no desarrollados, de acuerdo con las prioridades definidas en los planes de ordenamiento, por la de enajenación forzosa de los mismos, mediante subasta pública. En virtud de esta nueva figura, el sector industrial constructor o inmobiliario podrá sustituir a los propietarios de la tierra ociosa, pagando una compensación al propietario que no cumpla con la función social de la propiedad, es decir que no urbanice ni construya su inmueble dentro de los plazos señalados al efecto.

8. María Mercedes Maldonado. "Los avalúos como herramienta de gestión del plan de ordenamiento y el principio de la distribución de cargas y beneficios" (artículo derivado de la tesis doctoral Derecho a y de la ciudad y procesos de producción normativa en Colombia, Bogotá, 2000. convierte en la solución práctica a los múltiples problemas técnicos que surgen de la aplicación de la LDT. Tales principios son la función social y ecológica de la propiedad, la prevalencia del interés general sobre el particular y la distribución de las cargas y beneficios. De la lectura del texto de la LDT, y siguiendo a Maldonado, pueden extraerse así mismo otros principios que amplían y refuerzan su marco, cuales son: “el urbanismo como función pública", "el derecho del Estado a participar en las plusvalías de su acción urbanística no se reduce a la aplicación de un impuesto", "el derecho de urbanizar y de construir no está incorporado en el derecho de propiedad" y la "normativa ambiental como generadora de nuevos planteamientos jurídicos, éticos y políticos"8.

En síntesis, en la LDT se creó la plusvalía, al tiempo que se estableció la obligación para todos los municipios del país de diseñar y aprobar un Plan de Ordenamiento Territorial (РОТ) que tendría una vigencia de diez años, siendo la plusvalía una de las fuentes principales de ingresos del respectivo plan. De igual forma se dispuso que los concejos municipales, en virtud de la LDT, deberán adoptar mediante acuerdos la plusvalía, de conformidad con la potestad tributaria derivada de los concejos. 


\section{Naturaleza jurídica de la plusvalía}

La determinación de la naturaleza jurídica de la figura ha suscitado intensos debates entre los funcionarios de las administraciones tributarias y los académicos. De esta suerte, es posible hallar posiciones que afirman que la plusvalía no es un gravamen a la propiedad inmueble sino una nueva creación constitucional, en tanto que otros consideran que cuenta con las características jurídicas para clasificarla como un tributo.

Los primeros fundamentan su posición en un criterio de ubicación y definición normativa. Señalan, en primer término, que si la plusvalía fuera un tributo el constituyente la habría consagrado en el título XII (Del régimen económico y de la hacienda pública) y no en el título II (De los derechos, las garantías y los deberes), como en efecto lo hizo. En segundo lugar, atendiendo al tenor literal del artículo 82 de la Constitución, sostienen que se trata de una "participación" entendida como una nueva fuente de ingresos no tributaria de las entidades públicas. Y por último, alegan que en el Decreto Reglamentario de la Plusvalía 1599 de 1998 se calificó a la plusvalía de "mecanismo".

En términos jurídicos, la negación o afirmación del carácter tributario de la plusvalía conduciría a la consecuente anulación o convalidación de los principios constitucionales del sistema tributario colombiano que limitan la potestad impositiva del legislador, y que constituyen per se auténticas normas jurídicas. Puesto en otros términos, el carácter tributario de la plusvalía supondría el derecho de los ciudadanos a exigir que el poder legislativo en su ejercicio se ajuste al contenido de la Constitución Nacional.

\subsection{Definición}

Conforme a la jurisprudencia constitucional la plusvalía, al igual que la contribución de valorización tiene fundamento constitucional (arts. 82 y 317 C. N.), obedece a la realización práctica de los principios de solidaridad y equidad en la distribución de las cargas y beneficios públicos generados por la ejecución de obras públicas o por las acciones de planeamiento y puesta en marcha de proyectos para el manejo y defensa del suelo, como la incorporación de un área rural en 
el crecimiento de las ciudades, la autorización de un mayor aprovechamiento del suelo en edificación, bien sea elevando el índice de ocupación o el índice de construcción, o ambos a la vez, y constituye un recurso fiscal (cfr. Corte Constitucional, sentencia C-495 de 1998, M. P.: ANTONio BarRera CARbonelL).

En rigor, una análisis de la normatividad nos permite afirmar la naturaleza tributaria del instrumento en cuanto responde al criterio de "capacidad económica", derivado de la Constitución, y no sólo a la categoría genérica de prestación de carácter público como manifestación del poder de imperio del Estado?, al tiempo que la estructura jurídica del instrumento dispuesta en la LDT, según la definición de los hechos imponibles, y la prescindencia en la Constitución de la exigencia de una ley especial que regule esta categoría de ingreso público (como ocurre en materia de endeudamiento externo) apuntan a la reiteración del mismo postulado.

La plusvalía pertenece a la especie tributaria de las contribuciones (o "contribuciones especiales", como las denomina la doctrina para salvar la frecuente asimilación con

9. Sobre prestaciones de derecho público y su diferencia con las categorías tributarias, consultar JUAN MARTín Queralt. "La potestad tributaria", en AA. vv. Tratado de Derecho Tributario, Andrea Amatucci (dir.), t. I, Bogotá, Temis, 2001, p. 146. la noción de tributos) que gravan a un determinado grupo de personas atendiendo al denominado criterio del "beneficio". Esta clase de gravámenes ha sido definida en el modelo de Código Tributario para América Latina de la Organización de Estados Americanos y del Banco Interamericano de Desarrollo, así:

"Tributo que tiene como hecho generador beneficios derivados de la realización de obras públicas o actividades estatales y cuyo producto no debe tener un destino ajeno a la financiación de las obras o las actividades que constituyen el presupuesto de la obligación".

Desde esa perspectiva es claro que la plusvalía se origina en una actuación del Estado, que genera beneficios recuperados vía contribución para la financiación de la actividad estatal, que le dio origen, cual es la de financiar el desarrollo urbano, entendido como la organización de las actividades humanas en el entorno de las ciudades; además es un gravamen que limita el derecho de propiedad de un "grupo específico de personas que reciben un beneficio económico, con ocasión de las actividades urbanísticas que adelantan las entidades públicas (cfr. Sentencia, C-495 de 1998)". Sumado a lo anterior debemos recordar que en la exposición de motivos de la LDT 
se concibió a la plusvalía como una reorientación o reemplazo de la contribución de desarrollo municipal.

En ese orden de ideas, la plusvalía fue concebida en la Constitución Política de 1991 como un "derecho de las entidades públicas a participar en la plusvalía que genere su acción urbanística”, a partir del reconocimiento de que la propiedad inmueble experimenta aumentos de valor en virtud de decisiones administrativas, que por lo demás no son producto del esfuerzo individual de los propietarios. De ahí que parezca lógico que la comunidad, a través de las entidades públicas, recupere esos incrementos de valor mediante la figura tributaria de la plusvalía.

Por todas las consideraciones expuestas proponemos como definición de la plusvalía la siguiente:

Contribución especial de carácter territorial que grava a los propietarios o poseedores de predios ${ }^{10}$ que se beneficien por el mayor valor que generen las acciones urbanísticas municipales y distritales, dirigida a financiar el desarrollo urbano de los respectivos territorios.

Con lo anterior debemos concluir que la plusvalía en nuestra legislación es una contribución especial que grava la propiedad raíz de propietarios y poseedores de terrenos que experimenten un beneficio con ocasión de acciones urbanísticas de los municipios y distritos, que tiene una estructura propia, por lo demás novedosa en nuestro sistema tributario. Dicha estructura es la que nos proponemos estudiar a continuación, a partir de la noción de "hecho imponible", en sus cuatro aspectos (material, espacial, cuantitativo y temporal), con el fin de demostrar nuestra definición y, más allá, su conformidad con los principios constitucionales de la tributación.

\subsection{El hecho imponible de la plusvalía}

\subsubsection{Aspecto material}

El aspecto material del hecho imponible en la plusvalía fue definido en el artículo 74 de la LDT. En esa disposición se establece que constituyen hechos generadores de la plusvalía "las decisiones administrativas que configuran acciones urbanísticas según lo establecido en el artículo $8 .^{\circ}$ de esta ley, y que autorizan específicamente ya sea a destinar el inmueble

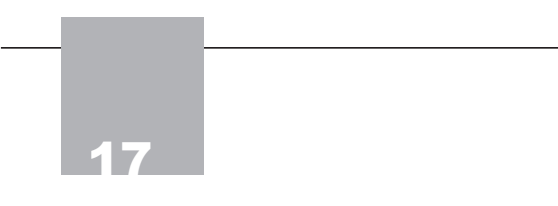

10. El artículo 11 de la Resolución 2555 de 1988 del IGAC define los predios como el inmueble perteneciente a una persona natural o jurídica, o una comunidad, situado en un mismo municipio, no separado por otro predio público o privado, y que forma parte de una misma explotación económica. 
a un uso más rentable, o bien a incrementar el aprovechamiento del suelo permitiendo una mayor área edificada, de acuerdo con lo que se estatuya formalmente en el respectivo Plan de Ordenamiento Territorial o en los instrumentos que lo desarrollen".

De conformidad con el artículo $8 .^{\circ}$ de la LDT, son decisiones administrativas que configuran acciones urbanísticas, entre otras, las siguientes: clasificar el territorio en suelo urbano, rural y de expansión urbana; establecer la zonificación y localización de los centros de producción, actividades terciarias y residenciales, y definir los usos específicos, intensidades de uso, las cesiones obligatorias, los porcentajes de ocupación, las clases y usos de las edificaciones y demás normas urbanísticas; calificar y localizar terrenos para la construcción de viviendas de interés social; y determinar y reservar terrenos para la expansión de las infraestructuras urbanas.

Si bien, las acciones urbanísticas generadoras de la plusvalía, en los términos de la LDT, deberán originar un "uso más rentable" o un "mejor aprovechamiento", dichos conceptos no fueron definidos por la LDT. Al respecto cabe anotar que el Plan de Ordenamiento Territorial de Bogotá, Decreto 619 de 2000, dice que para que se genere la participación en plusvalía las acciones urbanísticas deberán permitir un "aprovechamiento mínimo", establecido por las autoridades distritales.

De igual forma, el artículo 74 de la LDT prevé que las acciones urbanísticas deberán estar consagradas en los "planes de ordenamiento territorial o en los instrumentos que los desarrollen". Sobre los planes de ordenamiento territorial es pertinente señalar que en el artículo 41 de la Ley 152 de 1994, Ley Orgánica del Plan de Desarrollo, fueron consagrados como instrumentos básicos para estructurar el desarrollo de los municipios, junto con los planes de desarrollo municipal, y en el artículo 9. ${ }^{\circ}$ de la LDT fueron definidos como el "conjunto de objetivos, directrices, políticas, estrategias, metas, programas, actuaciones y normas adoptadas para orientar y administrar el desarrollo físico del territorio y la utilización del suelo".

Ahora bien, aunque la LDT omitió la definición de qué se entiende por "instrumentos que desarrollen los planes de ordenamiento territorial", para efectos de determinar las acciones urbanísticas generadoras de plusvalía, en el artículo $2 .^{\circ}$ de un proyecto de decreto reglamentario de la plusvalía, 
que actualmente se encuentra en discusión en el Ministerio de Desarrollo, se señala que se trata de los decretos que adoptan los planes parciales y demás decretos que desarrollen las autorizaciones previstas en el respectivo РОт. Conforme al artículo 19 de la LDT, los planes parciales o planes locales son instrumentos que desarrollan y complementan disposiciones de los planes de ordenamiento territorial, para áreas determinadas de suelo urbano y de expansión urbana, además de aquellas que deban desarrollarse mediante unidades de actuación urbanística, macroproyectos u otras operaciones urbanas especiales. Estos planes parciales o planes locales deberán ser adoptados por las autoridades municipales y distritales mediante decreto.

En síntesis, se entiende por hechos generadores en términos generales de la plusvalía las decisiones de la administración que configuren acciones urbanísticas que autoricen un "mayor aprovechamiento" o "uso más rentable", de acuerdo con lo establecido en los planes de ordenamiento territorial o en los instrumentos que los desarrollen, como es el caso de los planes parciales.

En ese orden de ideas, continúa el artículo 74 de la LDT señalando como hechos generadores:

3.2.1.1 La incorporación de suelo rural a suelo de expansión urbana o la consideración de parte del suelo rural como suburbano

Sobre este primer hecho generador debemos indicar que los planes de ordenamiento territorial deben clasificar el territorio de los municipios y distritos en suelo "urbano", "rural" y de "expansión urbana", y dentro de estás categorías ubicar las de suelo "suburbano y de protección". Dichos conceptos de clasificación del suelo fueron definidos en el capítulo IV, artículos 30-35 de la LDT.

De igual manera, en el parágrafo $2 .^{\circ}$ del artículo 260 del Proyecto de Estatuto de Ingresos de las Entidades Territoriales (en adelante el "Proyecto de Estatuto") se estableció que para que un predio sea incorporado al perímetro urbano se requiere que en el Plan de Ordenamiento Territorial sea clasificado como "suelo de expansión", y que posteriormente con el plan parcial se incorpore. 
Sobre las rentas urbanas de Bogotá se estableció que evidentemente éstas son más altas en el suelo urbano. Esto se traduce en mayores precios del suelo que generan "plusvalores". En efecto, "en una ciudad de las características de Bogotá los precios del suelo varían con la distancia al centro. Entre más cerca se encuentre un terreno del centro tiene un mayor valor. Entre las razones se pueden relacionar menores costos de desplazamiento, mejor acceso a servicios y mayores rentas. En particular, cabe destacar el impacto de este último factor, dado que el precio del suelo puede verse como una renta capitalizada ${ }^{11}$. Es claro que el suelo urbano tiene un mejor nivel de renta que el suelo agrícola y por ende el cambio en la clasificación se traduce en un mayor precio del terreno"12.

\subsubsection{El establecimiento o modificación del régimen}

o la zonificación de usos del suelo

La LDT no definió la noción de "cambio de uso", por el contrario, en el parágrafo del artículo 74 establece que dicho

11. Departamento Administrativo de Planeación Distrital. Los precios del suelo en Bogotá: 2000-2010. Las plusvalías después del POT, Bogotá, 2001.

12. Secretaría de Hacienda Distrital. Soporte técnico: proyecto de reforma del Estatuto Tributario $2001 \mathrm{del}$ Distrito de Bogotá. concepto deberá ser definido mediante reglamentación del Gobierno nacional. Sobre el particular, la parte final del parágrafo del artículo 3. ${ }^{\circ}$ del Decreto 1599 de 1998 la definió como "modificación normativa que permite destinar los inmuebles de una zona o subzona geoeconómica homogénea o de un área morfológica homogénea a un uso diferente". Las "zonas geoeconómicas homogéneas" fueron definidas en el artículo 6. ${ }^{\circ}$ del Decreto 1420 de 1998 como "el espacio que tiene características físicas y económicas similares, en cuanto a topografía, normas urbanísticas, servicios públicos domiciliarios, redes de infraestructura vial, tipología de las construcciones, valor por unidad de área de terreno, áreas morfológicas homogéneas y la estratificación socieconómica".

Básicamente estas zonas se establecen a partir de un análisis económico de las zonas homogéneas físicas, las cuales a su vez se determinan en función de su topografía, uso, servicios públicos y de sus vías. El análisis económico involucra todos los aspectos que inciden en la valoración del suelo y que pueden constituirse en focos de afectación positiva o negativa (parques recreativos, centros comerciales, zonas verdes, transporte, arroyos, contaminación auditiva, visual u olfativa, entre otros). Para adelantar la zonificación de la ciudad con base en estos 
planos se deben agrupar las zonas que sean homogéneas bajo el criterio de calidad de vida, y se debe numerar cada grupo ordenándolos del peor al mejor, de tal manera que el número menor corresponda al grupo de zonas con calidad de vida más baja ${ }^{13}$.

En el mismo sentido, el artículo 9. ${ }^{\circ}$ del proyecto de decreto propone como definición de "cambio de uso" "la autorización mediante norma para destinar los inmuebles de una zona a uno o varios usos diferentes a los permitidos por la norma anterior".

Respecto de las rentas urbanas originadas en "cambios de uso", en el caso de Bogotá se sostiene: "En una ciudad el cambio de uso de un sector hacia uno superior genera un incremento en la renta del suelo. La renta de los predios destinados al comercio es mayor que la de los predios destinados a la vivienda, sin embargo, al graficar el comportamiento de la renta en relación con la distancia al centro, se observa una pendiente más pronunciada que para los predios destinados a la vivienda. Como se menciona antes, un mayor nivel de renta se refleja en un mayor nivel de precios, dado que uno de los factores para la fijación del precio es la capitalización de la renta" ${ }^{14}$.

3.2.1.3 La autorización de un mayor aprovechamiento del suelo en edificación, bien sea elevando el índice de ocupación o el índice de construcción, o ambos a la vez

La definición del "índice de ocupación", "índice de construcción" y "cambio de uso", de conformidad con el artículo 74, parágrafo de la LDT, le corresponderá al Gobierno nacional. En consecuencia, el parágrafo del artículo $3 .^{\circ}$ del Decreto 1599 de 1998 estableció: "Aprovechamiento del suelo es el número de metros cuadrados de edificación permitidos por la norma urbanística por cada metro cuadrado de suelo; índice de ocupación es la proporción del área del suelo que puede ser objeto de construcción; índice de construcción es la relación entre el área construida de la edificación y el área del suelo del predio objeto de la construcción; y cambio de uso es la modificación normativa que permite destinar los inmuebles de una zona o subzona geoeconómica homogénea o de un área morfológica homogénea a un uso diferente".

13. Información sectorial en: [www.dnp.gov.co] 14. Secretaría de Hacienda Distrital, 2001. 
En efecto, “autorizar la construcción de un mayor número de pisos implica densificar el terreno. Cuando esto ocurre se ceden a los dueños de los terrenos mayores derechos sobre el espacio aéreo de la ciudad. Autorizar una mayor edificabilidad resulta en la intensificación del uso del capital sobre el mismo terreno. La consecuencia es, como en los casos anteriores, una mayor renta para el mismo terreno y por ende un mayor precio" 15 .

Por último, el artículo 87 de la LDT previó un cuarto hecho generador así:

\subsubsection{Participación en plusvalía por ejecución de obras públicas}

En estricto sentido, este hecho generador coincide con el de la contribución de valorización que grava, de conformidad con el artículo 1. ${ }^{\circ}$ del Decreto Legislativo 1604 de 1966, las propiedades raíces que se beneficien con la ejecución de obras

15. Ibídem.

16. Considerando el carácter especial de la ley por la cual se expide el Estatuto de las Entidades Territoriales, y el principio de unidad de materia, constitucionalmente es posible suprimir un supuesto de la ley. de interés público local. Al respecto es pertinente recordar que el propósito de la plusvalía es gravar los aumentos en la renta de la tierra originados en "acciones urbanísticas", por fuera del esfuerzo individual de los propietarios, que responden netamente a decisiones administrativas, y no limitar el ejercicio del derecho de propiedad en virtud de inversiones en obras públicas que generen un incremento de valor.

Dicha situación parece advertirse en el proyecto de estatuto $^{16}$, al igual que en el proyecto de decreto, cuando se propone eliminar el supuesto de generación de plusvalía por la realización de obra pública. En ese orden, el cuarto hecho generador de la plusvalía previsto por la LDT, de ser aprobado el proyecto de estatuto estaría derogado.

En resumen, son hechos generadores de la participación en plusvalías las acciones urbanísticas que establezcan una nueva clasificación del suelo, cambio de uso, mejor aprovechamiento en índice de ocupación o de densidad o la construcción de una obra pública. Así las cosas, los hechos generadores previstos en la LDT deberán determinarse en los planes de ordenamiento territorial, y en los instrumentos que los desarrollen. Para tal efecto, los planes de ordenamiento territorial o los instrumentos que los desarrollen deberán también determinar las zonas o subzonas beneficiarias y hacer referencia explícita a la 
participación en plusvalía y su incidencia sobre las finanzas del respectivo municipio (art. 21 Dcto. 1599/98).

Así mismo, se deberán adoptar, a través de acuerdos municipales y distritales, las normas relativas a la plusvalía. Sobre ese punto, ante la omisión de la LDT, de la lectura del artículo 17 del proyecto de decreto parece deducirse que se deberán expedir con posterioridad a los planes de ordenamiento territorial, en cuanto éstos son los que determinan la destinación particular del tributo. De cualquier forma, es claro que el cobro de la plusvalía en las entidades municipales y distritales requiere previa adopción, mediante acuerdo, como ocurre frente a todos los tributos territoriales en virtud de la potestad derivada de los concejos municipales y distritales.

Y para finalizar con el aspecto material de la plusvalía, la LDT previó un supuesto que coincide con lo previsto por el proyecto de estatuto en el parágrafo $4 .^{\circ}$ del artículo 269, en el que no se configura ningún hecho generador sobre esta clase de inmuebles ${ }^{17}$. En el parágrafo $4 .^{\circ}$ del artículo 83 se previó: "Los municipios podrán exonerar del cobro de la participación en plusvalía a los inmuebles destinados a vivienda de interés social, de conformidad con el procedimiento que para el efecto establezca el Gobierno nacional". En consecuencia, los propietarios de inmuebles destinados a vivienda de interés social, en virtud de los planes de ordenamiento territorial y la política municipal sobre vivienda de ese carácter, en el caso en que sobre sus terrenos recaiga algún hecho generador, con posterioridad a la liquidación de la contribución, podrán solicitar ser exonerados de su pago. Para tal efecto, los concejos deberán expedir un acuerdo que puede ser el mismo en el que se adopte la plusvalía otorgando el beneficio, previa suscripción de un contrato entre los beneficiarios y la administración.

\subsubsection{Aspecto espacial}

La definición del aspecto espacial del hecho imponible o segundo aspecto de la plusvalía se omite tanto en la Constitución como en la LDT. Sin embargo, es posible deducir que puesto que se trata de un gravamen a la propiedad raíz, la plusvalía a su vez se limita al espacio en el cual tenga vigencia el respectivo Plan de Ordenamiento Territorial, en cuanto es un instrumento de financiación del mismo. Con esto se grava

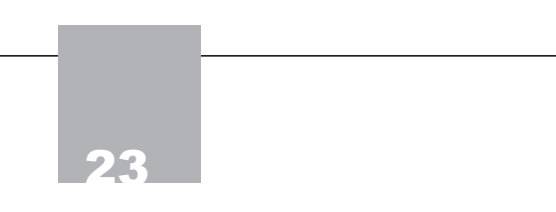

17. Las exenciones o supuestos de no surgimiento de la obligación tributaria constitucionalmente son permitidas en razón de criterios de justicia y equidad, $\mathrm{y}$, en últimas, de política fiscal. 
estrictamente a las propiedades inmobiliarias ubicadas en los municipios y distritos del país.

De hecho, la Constitución Política consagra en el artículo 82 que las "entidades públicas" serán las acreedoras de la plusvalía que genere su acción urbanística. El artículo 41 de la Ley 152 de 1994, Ley Orgánica del Plan de Desarrollo, establece que los municipios deben adoptar los planes de ordenamiento territorial. Y la LDT reitera que los municipios y distritos deben adoptar los planes de ordenamiento territorial y reglamentar los usos del suelo en sus respectivos territorios; y en el artículo 73, que los "concejos municipales y distritales" establecerán, mediante acuerdos de carácter general, las normas para la aplicación de la participación en la plusvalía en sus respectivos territorios.

De lo anterior se deduce que la plusvalía es una contribución de propiedad de las entidades territoriales, cuyo sujeto activo lo constituyen los municipios y los distritos del lugar en que se ubiquen los inmuebles. Por tanto, están facultadas para su recaudo las secretarías de hacienda municipales y distritales,

18. Corte Constitucional, Sentencia C495 de 1998, M. P.: ANTONIO BARRERA CARbonell. de conformidad con los planes de ordenamiento territorial. Igualmente, en la LDT se prevé que las áreas metropolitanas participen de la plusvalía generada por las obras públicas que ejecuten, de acuerdo con los planes integrales de desarrollo metropolitano.

De otro lado, aunque la Constitución Política y la LDT omiten nuevamente la determinación de los sujetos pasivos de la participación en plusvalía, del texto de la LDT, y en particular del inciso final del parágrafo $3 .^{\circ}$ del artículo 83 , que consagra la solidaridad entre propietarios y poseedores, se puede concluir que serán deudores fiscales los "propietarios o poseedores" de los predios beneficiados por las acciones urbanísticas. Confirma nuestra conclusión la previsión expresa del artículo 261 del proyecto de estatuto.

Es pertinente en este punto recordar la Sentencia C-495 de 1998, a la que hacíamos referencia en el ítem sobre la naturaleza jurídica de la plusvalía. En dicho fallo la Corte consideró que, al igual que la valorización, esta contribución recae exclusivamente sobre un grupo determinado de sujetos pasivos: afecta a un grupo específico de personas que reciben un beneficio económico, con ocasión de las actividades urbanísticas que adelantan las entidades públicas ${ }^{18}$. 


\subsubsection{Aspecto cuantitativo}

La LDT consagró un procedimiento específico para la determinación del mayor valor en cada uno de los cuatro hechos generadores de la plusvalía.

En los artículos 75 y 76 se estableció que para determinar el efecto plusvalía ${ }^{19}$ por "incorporación de suelo rural a expansión urbana o por calificación de parte del suelo rural como suburbano" (primer hecho generador de la LDT), y por "el establecimiento o modificación del régimen o la zonificación de usos del suelo" (segundo hecho generador), deberá realizarse una comparación del valor de los predios por zonas geoeconómicas homogéneas, antes y después de la norma urbanística que genera el incremento. Al valor de los predios antes de la acción urbanística se denomina precio inicial, y al posterior, precio de referencia. La diferencia entre dichos valores será la plusvalía o mayor valor, la cual finalmente se multiplicará por el total de la superficie objeto del tributo, es decir, por el área beneficiada de cada predio.

En ese orden de ideas, el artículo 84 de la LDT estableció que el Instituto Agustín Codazzi, la entidad que haga sus veces o los peritos técnicos debidamente inscritos en las lonjas o instituciones análogas, establecerán los precios comerciales ${ }^{20}$, y determinarán los precios iniciales y de referencia. De la misma manera, el inciso final del artículo 13 del Decreto 1599 de 1998 consagró que el cálculo del efecto plusvalía por dichas entidades se sujetaría a los procedimientos señalados en el Decreto 1420 de 1998.

El artículo 22 del Decreto 1420 de 1998, así mismo, consagró algunos parámetros que deberán tenerse en cuenta en la realización de los avalúos comerciales por zonas o subzonas geoeconómicas homogéneas. Básicamente, dichos aspectos consideran particularidades del terreno las construcciones y los cultivos. Y la Resolución 762 de 1998 del Instituto Geográfico Agustín Codazzi determinó la metodología que debía emplearse en la realización de los avalúos comerciales de la plusvalía.

Al final, la LDT previó que el efecto plusvalía debería actualizarse de conformidad con el Índice de Precios al Consumidor hasta el momento de su exigibilidad. Dicho índice es muy criticado porque no considera la tierra, y con el tiempo

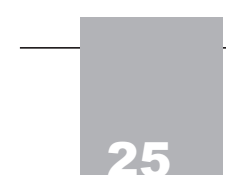

19. Como veremos, el efecto plusvalía corresponde en rigor a la noción de base gravable de la contribución de plusvalía a la que se le aplican las tarifas correspondientes.

20. El parágrafo del artículo $8 .^{\circ}$ del proyecto de decreto establece la determinación de las zonas o subzonas geoeconómicas homogéneas y se sujetará a la Resolución 2555 del Instituto Geográfico Agustín Codazzi o aquellas que la modifiquen. 
los precios de los terrenos actualizados pueden no corresponder con los precios del mercado inmobiliario ${ }^{21}$.

Si bien la LDT determinó que para calcular el efecto plusvalía debía determinarse el valor comercial de los inmuebles por zonas u subzonas geoeconómicas homogéneas antes de la acción urbanística (o precio inicial), no previó cuál sería la fecha de esos avalúos. Es decir, aunque se estableció la forma como debía practicarse un avalúo inicial, no se determinó la fecha de antelación a la normativa urbanística que debía considerarse para tales efectos. Al respecto surgió la discusión en las administraciones de si el precio inicial debería retrotraerse a la fecha de expedición de la Ley 388 o ser posterior a su vigencia. Para solucionar este vacío legislativo, el artículo 31 del Decreto 1420 de 1998 dispuso que la fecha sería el 24 de julio de 1997, tratándose de la expedición de los POT, y el año anterior a la adopción, cuando se tratara de instrumentos que los desarrollaran.

Sin embargo, el artículo $8 .^{\circ}$ del proyecto de decreto propone "modificar esos términos señalando que el precio inicial será

21. En contraste, en el caso del impuesto predial existe un índice especial.

22. Juan Rafael Bravo Arteaga. "El elemento temporal: la vigencia de la ley tributaria", en AA. vv. Teoría del impuesto sobre la renta, Bogotá, Instituto Colombiano de Derecho Tributario, 1995, p. 74. el precio de mercado que tuvieran dichos inmuebles treinta (30) días antes de la fecha en que entre en vigencia el Plan de Ordenamiento Territorial o los instrumentos que lo desarrollen, y contengan los hechos generadores de la participación en plusvalía".

De cualquier forma, es evidente que el señalamiento de la fecha de estos avalúos obedece a un criterio arbitrario del reglamento, pues no hay justificación alguna para que los precios comerciales sean determinados con una u otra fecha, si bien en la experiencia de los municipios, dependiendo de los valores que arroje el mercado inmobiliario para tales fechas, determinará los mayores valores, y con ello los recursos esperados.

Con todo, teniendo en cuenta que la determinación del precio inicial (anterior a la norma urbanística) es un aspecto de la base gravable de la contribución, esto nos lleva a concluir que estamos en presencia de un tributo de período, en contraste con la valorización que es de causación instantánea. En efecto, son tributos de período aquellos cuya base gravable está constituida por hechos ocurridos con anterioridad, y sea el resultado de sumar y restar determinados factores para llegar a la cifra materia de gravamen ${ }^{22}$. En el caso de la plusvalía, la base 
gravable está constituida por el aumento de valor experimentado por un predio en un período determinado (una fecha anterior y otra posterior al surgimiento del hecho generador).

En síntesis, tratándose de los hechos generadores de "incorporación de suelo rural a urbano o suelo rural a suelo de expansión urbana" y "el establecimiento o modificación del régimen o la zonificación de usos del suelo" es necesario que las entidades municipales, a través del Instituto Geográfico Agustín Codazzi, Catastro y demás entidades análogas, determinen los precios iniciales (o precios anteriores a la normativa urbanística), y precios de referencia (precios posteriores a la normativa urbanística) a partir de avalúos comerciales. Los precios iniciales corresponden al precio de mercado de los inmuebles beneficiarios del 24 de julio de 1997, de acuerdo con el Decreto reglamentario 1420.

La base gravable o efecto plusvalía consiste en la diferencia entre los precios de referencia y los precios iniciales. De conformidad con el proyecto de decreto se ha entendido que la realización de los avalúos debe hacerse dentro de la noción de zona o subzona geoeconómica homogénea, si bien comprende otras nociones definidas en el Decreto 1599 de 1998. Y, por último, la metodología para realizar los avalúos está contenida en la Resolución 762 de 1998 del IGAC, y la base gravable deberá ser actualizada según el IPC al momento de exigibilidad de la plusvalía.

En lo referente al tercer hecho generador, originado en la autorización de un mayor aprovechamiento del suelo en edificación, bien sea elevando el índice de ocupación o el indice de construcción, o ambos a la vez, la LDT consagró en el artículo 74 un procedimiento diferente para la determinación de la base gravable. Esta norma presenta una redacción confusa que se traduce en una base gravable confiscatoria, pues comprende una cuantificación superior al hecho generador que la produce. En otros términos, si sabemos que la noción de plusvalía es correlativa a mayor valor originado en una acción urbanística, la base gravable debe limitarse al mayor valor (potencial adicional) que experimente el área de terreno objetode la contribución, que corresponde al incremento en la renta y no a la renta en su totalidad.

Probablemente, con un sentido práctico, el propósito de la norma en comento era eliminar el segundo avalúo, que se practica para determinar la base gravable de los dos primeros 
hechos generadores. Sin embargo, el texto de la norma en la práctica de los municipios ha generado inconvenientes.

En efecto, en el proyecto de estatuto de ingresos de las entidades territoriales, en los artículos 263 y 268 se advirtió tal situación. En virtud de estos artículos, el procedimiento para la determinación de la base gravable de los hechos generadores de la plusvalía requiere un avalúo inicial, anterior a la norma urbanística, y otro posterior, cuya diferencia determinará el mayor valor. El efecto plusvalía equivaldrá a la multiplicación del número de metros cuadrados beneficiados con la norma por el mayor valor. Es decir que en el caso de plusvalía por "mejor aprovechamiento" (y aun en los otros supuestos normativos) es necesario practicar dos avalúos, cuya diferencia será aplicada al número de metros cuadrados beneficiados (y no al área total del terreno).

Al final, en lo concerniente al hecho generador de construcción de obra pública, el artículo 87 de la Ley 388 de 1997 previó que el efecto plusvalía se calculará antes, durante o dentro de los seis meses posteriores a la conclusión de las obras, sin que constituya límite el costo estimado o real de la ejecución de las obras.

Esa norma permite avanzar sobre la contribución de valorización, en cuanto no se limita el mayor valor al costo estimado de ejecución de las obras, y permite cobrar el tributo aun seis meses después de concluidas las obras. En otras palabras, la valorización se diferencia de la plusvalía por obra pública, en que se limita al costo de las inversiones estatales, mientras que esta última recupera todo el aumento de valor experimentado por los predios beneficiarios (y con esto sería un verdadero instrumento de recuperación de plusvalías); igualmente, en este aspecto la posibilidad de cobrar la plusvalía con posterioridad a la finalización de las obras, es una diferencia con la valorización, que en términos políticos para las finanzas territoriales puede significar la aprobación por los Concejos de obras de interés general, supeditando el cobro a las administraciones futuras.

De otra parte, en el supuesto que sobre un mismo inmueble se produzcan simultáneamente dos o más hechos generadores en virtud de la normativa urbanística, de acuerdo con el parágrafo $1 .^{\circ}$ del artículo 79 de la LDT, en el cálculo del mayor valor por metro cuadrado se tendrán en cuenta los valores acumulados, cuando a esto haya lugar. 
En resumen, la base gravable de los hechos generadores de la plusvalía corresponde a los "mayores valores" 23 asignados a los terrenos con ocasión de la normativa urbanística. Para el caso de la "clasificación del suelo rural en urbano o suelo de expansión", y en el de "cambio de uso", el procedimiento para la determinación consiste en la práctica de un avalúo anterior a la norma urbanística que contempla el hecho generador, y un avalúo posterior a la misma. La diferencia entre dichos avalúos se entiende sea la plusvalía, que multiplicada por el área objeto del tributo determinará el efecto plusvalía.

En el caso del tercer hecho generador, o plusvalía por "mejor aprovechamiento", el mayor valor se determinará por un avalúo anterior a la norma, que se multiplicará por el potencial adicional que permite la nueva norma, y a su vez este resultado se le aplicará al área objeto del tributo. Y en cuanto al cuarto hecho generador, o plusvalía por obra pública, el mayor valor corresponde a la valorización que experimenten los predios, sin limitación al costo de la obra. Finalmente, si existe concurrencia de hechos generadores, sólo en los casos en que se trate del segundo y tercer hechos será necesario incorporar en los avalúos los respectivos incrementos.

Continuando con el aspecto cuantitativo del hecho imponible de la plusvalía, el artículo 79 de la Ley de Desarrollo Territorial previó que los concejos municipales o distritales, por iniciativa del alcalde, establecerán la tarifa de la plusvalía generada, la cual podrá oscilar entre el $30 \%$ y el $50 \%$ del mayor valor por metro cuadrado, sin perjuicio de tarifas diferenciales al interior de zonas o subzonas, siempre que estén dentro de dicho rango.

Por tanto, los concejos municipales y distritales, a iniciativa de los alcaldes, deberán adoptar mediante acuerdos las tarifas aplicables en sus respectivos territorios. Dicha adopción de la tarifa, en virtud del proyecto de decreto, puede hacerse dentro de los planes de ordenamiento territorial o en los acuerdos de carácter general que adopte la plusvalía. Este criterio nos parece sano siempre que haya unidad de materia entre la normativa urbanística que propicia las plusvalías y la tarifa que se cobre por las mismas; y en cuanto la LDT, sólo previó que debían adoptarse por los concejos.

En cuanto a la diferencia de tarifas al interior de las zonas o subzonas geoeconómicas homogéneas en el Distrito Capital

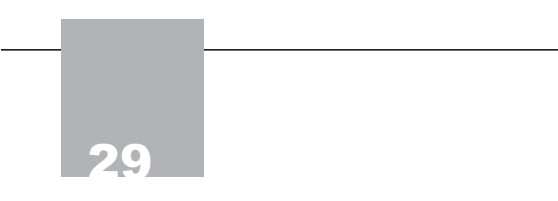

23. El concepto de "mayor valor" o "plusvalía" se contrapone a la noción de "minusvalías", que suponen disminución del valor. En el procedimiento consagrado en la Ley 388 de 1997 , para la fijación de los avalúos se contemplan recursos para la discusión de los mismos, en los eventos en que los contribuyentes no estén conformes con los mismos. 
se sostuvo que "no es conveniente que convivan dos tasas de participación en el mismo momento del tiempo. Establecer decisiones administrativas discrecionales para la determinación de la tasa a cargo abre espacios para la corrupción y distorsiona la transparencia hacia los contribuyentes. Además, la instauración de la participación en la plusvalía permitirá separar el mercado de la tierra de la actividad empresarial del desarrollo urbano" $"$.

Consideramos que ese comentario no resulta del todo afortunado si recordamos que el principio de equidad tributaria consagrado en el artículo 363 de la Constitución Política apunta a garantizar que las leyes en materia tributaria traten de igual manera a quienes se encuentran en la misma situación, y de manera diferente a quienes se encuentren en supuestos disímiles. De ese modo, el establecimiento de tarifas diferenciales frente a un gravamen, como lo es la contribución por plusvalía, asegura no sólo la equidad tributaria, sino también el principio de progresividad de los tributos.

24. Secretaría de Hacienda Distrital, 2001, 20 .

\subsubsection{Aspecto temporal}

Por último, en lo concerniente al aspecto temporal del hecho imponible de la plusvalía es preciso hacer las siguientes consideraciones: en materia tributaria hay que distinguir entre los conceptos de nacimiento, causación y exigiblidad de la obligación tributaria.

En la Ley de Desarrollo Territorial se estableció la obligación para los municipios y distritos de expedir los planes de ordenamiento territorial y de adoptar mediante acuerdo de carácter general la plusvalía. Los planes de ordenamiento territorial prevén los hechos generadores de la contribución por plusvalía en sus respectivos territorios. Los concejos municipales y distritales deben adoptar la plusvalía mediante acuerdo de carácter general.

La potestad impositiva derivada de los concejos implica que éstos adopten los tributos creados por ley, y el principio de legalidad exige que los tributos sean adoptados con anterioridad a la realización de los hechos generadores. Esa sería la finalidad en los municipios y distritos del acuerdo de carácter general. Empero, puesto que la Ley 388 de 1997 determinó que en los planes de ordenamiento territorial estarían previstos los hechos generadores, surge la discusión acerca de cuál es el 
momento del nacimiento de la obligación de pagar la plusvalía, si se parte de la premisa de que los hechos generadores son un elemento de la obligación tributaria (corresponde al aspecto material del hecho imponible que desarrollamos en el primer aparte de este capítulo).

Siendo estrictos en el respeto al principio de legalidad, tendremos que llegar a la conclusión de que el nacimiento de la obligación de pagar la plusvalía nace con los planes de ordenamiento territorial, en cuanto con éstos se realizan los hechos generadores. En ese orden, los acuerdos serían desarrollo de la autorización legal que permite la adopción de los tributos, y por ende deberían ser expedidos con anterioridad a los planes; en caso contrario vulneraría el principio constitucional de legalidad de los tributos, lo que supondría la inconstitucionalidad de un tributo cuyo hecho generador sea anterior al acuerdo que lo adopta.

El Consejo de Estado, en sentencia del 13 de octubre de 1993, sobre el principio de legalidad en los tributos de período, señaló que toda norma que afecte los elementos estructurales de un gravamen es "reguladora" de la norma misma, y por ello si se trata de un tributo de período, sólo podrá aplicarse para el período que comience después de iniciar su vigencia. Con todo, podríamos decir que tanto el acuerdo que adopta la plusvalía como su decreto reglamentario deben ser anteriores a la realización del hecho generador que se configura con los planes de ordenamiento territorial.

En el caso de la plusvalía, una vez adoptada y expedidos los planes de ordenamiento territorial, estaríamos frente al supuesto de su causación. De ese modo, en los incisos segundo y tercero del artículo 13 del Decreto 1599 de 1998 y del artículo 80 de la ley se estableció que dentro de los cinco días hábiles siguientes a la adopción del РОт, el alcalde solicitará a las entidades respectivas que procedan a estimar el mayor valor por metro cuadrado en cada una de las zonas. Dichas entidades contarán con un término de sesenta días hábiles para ejecutar lo solicitado.

De conformidad con la ley, una vez determinado el efecto plusvalía por el IGAC o entidad análoga, el alcalde deberá liquidar la plusvalía para cada inmueble objeto de la misma y aplicará las tarifas autorizadas por el Concejo, dentro de los cuarenta y cinco días siguientes. Más adelante, el alcalde cuenta con el término de treinta días hábiles para expedir el acto 
administrativo que la determina, y para notificarlo a los propietarios lo hará mediante tres avisos. Contra la decisión de la administración procede el recurso de reposición, que será resuelto por la misma en el término de un mes si se cuestiona el avalúo. Una vez la decisión de la administración quede en firme, para efectos de publicidad frente a terceros se ordenará la inscripción en el folio de matrícula inmobiliaria del bien, de tal suerte que para que puedan registrarse actos de transferencia de dominio se requerirá certificado de la administración, en el que conste el pago de la plusvalía.

En resumen, los términos de la ley prevén: cinco días para que el alcalde decrete los avalúos; sesenta días para que el IGAC o entidad autorizada los practique; cuarenta y cinco días para que el alcalde liquide la plusvalía; treinta días para que se publique el acto administrativo que liquida el tributo; un mes para que el alcalde decida los recursos de reposición contra los avalúos. Es decir, de conformidad con la ley, dentro de los 170 días siguientes a la expedición de los planes de ordenamiento territorial, las plusvalías para cada predio deberán estar liquidadas.

No obstante, si bien la ley previó que el IGAC sería una de las entidades autorizadas para realizar los avalúos, y que de cualquier forma es la segunda instancia de las decisiones de otras entidades, no consideró dentro del término de liquidación los términos correspondientes a imposición, trámite y decisión de los recursos dispuestos por el Decreto 1420 de 1998, y, en últimas, de la Resolución 2555 de 1998 del IGAC.

En el proyecto de estatuto esta cuestión se resuelve en el artículo 265, que le otorga al alcalde un plazo máximo para liquidar la plusvalía de doce meses. En ese término el alcalde deberá decretar los avalúos, la entidad contratada los practicará, se surtirá el trámite de discusión ante estas entidades, y el alcalde liquidará la plusvalía. Además el artículo 266 del proyecto consagra un término posterior de diez días para publicar el efecto plusvalía por zonas, cinco días para interposición de reposición ante la administración y un mes para que ésta decida el recurso. En conclusión, en el proyecto de estatuto se estableció un término de un año y cuarenta y cinco días para el proceso de liquidación y discusión de las plusvalías, que puede resultar más ajustado a la realidad.

Paradójicamente, el artículo 262 del proyecto de estatuto estableció como momento de causación de la contribución 
por plusvalía la fecha de expedición de los planes de ordenamiento territorial o de los instrumentos que los desarrollen. Respecto a esta norma es pertinente señalar que si tenemos claro que la obligación de pagar el tributo surge con la determinación del monto a cargo, previo nacimiento de la obligación en virtud de la realización del hecho generador, la plusvalía se entenderá causada cuando sea liquidada. En otros términos, cuando el acto administrativo del alcalde que liquida el tributo quede en firme se entenderá que surge para los poseedores o propietarios de inmuebles beneficiados por los planes de ordenamiento territorial o instrumentos que los desarrollen la obligación de pagar la contribución por plusvalía.

Así las cosas, una vez nazca y se cause la obligación, la ley difiere el momento de su exigibilidad. Al respecto, el artículo 83 de la LDT dispuso que la plusvalía sólo será exigible en el momento en que se presente para el propietario o poseedor del inmueble, respecto del cual se haya declarado un efecto de plusvalía, una cualquiera de las siguientes situaciones: solicitud de licencia de urbanización o construcción, aplicable para cualquiera de los hechos generadores de que trata el artículo; cambio efectivo de uso del inmueble, aplicable para la modificación del régimen o zonificación del suelo; actos que impliquen transferencia del dominio sobre el inmueble, aplicable al cobro de la participación en la plusvalía de que tratan los numerales 1 y 3 del referido artículo 74; mediante la adquisición de títulos valores representativos de los derechos adicionales de construcción y desarrollo, en los términos que se establece en los artículos 88 y siguientes de la LDT.

En los artículos 88,89 y 90 de dicha ley se prevén los derechos adicionales de construcción y desarrollo a los que hace referencia el numeral 4 del artículo transcrito, que básicamente consiste en un mecanismo de recuperación anticipada de los mayores valores por las administraciones.

En conclusión, es diferente el momento del nacimiento, causación y exigibilidad de la obligación tributaria. En el caso de la plusvalía es claro que la obligación nace con el acuerdo que la adopta, que por lo demás, con ocasión del principio de legalidad de los tributos, debe ser anterior a la ocurrencia de los hechos generadores. La causación se da con la liquidación del efecto plusvalía y aplicación de la tarifa por el respectivo alcalde; y posteriormente la exigibilidad se da en unos supuestos taxativos previstos en la ley. De ello podemos

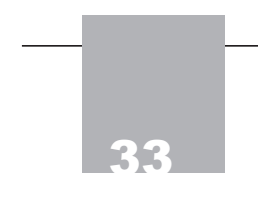

(1)


concluir también que mientras en la valorización la causación y exigibilidad se dan en un mismo instante, en la plusvalía estos momentos se difieren en el tiempo.

Sobre la exigibilidad es también pertinente anotar que el proyecto de estatuto, en el parágrafo $5 .^{\circ}$ del artículo 269 , prevé que como el pago de la plusvalía se hace exigible en oportunidad posterior a la determinación del efecto plusvalía por metro cuadrado, éste se ajustará cada año a partir del primero de enero, en un porcentaje igual a la variación del "índice de precios de venta de la propiedad raíz del departamento, certificado por las lonjas de propiedad raíz de la jurisdicción". Con esta disposición se pretende corregir el error de la ley que estableció que los tributos a cargo de los sujetos beneficiarios de la plusvalía se actualizarían con el IPC hasta el momento de su exigibilidad.

Por último, el artículo 85 de la citada ley estableció la destinación específica del tributo: "Compra de predios para desarrollar planes o proyectos de vivienda de interés social, construcción o mejoramiento de infraestructuras viales, de servicios públicos domiciliarios, áreas de recreación y equipamientos sociales para la adecuación de asentamientos urbanos en condiciones de desarrollo incompleto o inadecuado; ejecución de proyectos y obras de recreación, parques y zonas verdes y expansión y recuperación de los centros y equipamientos que conforman la red del espacio público urbano; financiamiento de infraestructura vial y de sistemas de transporte masivo de interés general; actuaciones urbanísticas en macroproyectos, programas de renovación urbana u otros proyectos que se desarrollan a través de unidades de actuación urbanística; pago de precio o indemnizaciones por acciones de adquisición voluntaria o expropiación de inmuebles, para programas de renovación urbana; y fomento de la creación cultural y el mantenimiento al patrimonio cultural del municipio o distrito, mediante la mejora, adecuación o restauración de bienes inmuebles catalogados como patrimonio cultural, especialmente en las zonas de la ciudad declaradas como de desarrollo incompleto o inadecuado".

En ese orden de ideas, la plusvalía en el marco de la política fiscal de los municipios y distritos compromete la distribución inequitativa de la riqueza hacia una progresiva distribución del gasto. La financiación de vivienda de interés social, la 
dotación en infraestructura de servicios hacia sectores que carezcan de los mismos, la financiación de sistemas masivos de transportes y de macroproyectos celebrados con el sector privado para el desarrollo urbano, son la clase de gastos públicos que se consideran redistributivos.

De hecho, se ha sostenido que los "los gastos públicos que consisten en erogaciones con el fin de redistribuir ingresos, financiados con recursos tributarios, surten los efectos redistributivos deseados si los tributos elegidos inciden sobre categorías de personas diferentes de los beneficiarios del gasto, según los propósitos del Estado y la idoneidad de los medios empleados" 25 . En el mismo sentido, "la redistribución del ingreso será progresiva si los beneficiarios del gasto pertenecen a un sector de ingresos más bajos que aquel sobre el cual recae la incidencia del tributo. Será regresiva si los beneficiarios del gasto pertenecen a un sector de ingresos más elevados que aquel sobre el cual inciden los tributos elegidos". De tal suerte que si consideramos que la participación en plusvalías grava a los propietarios y poseedores de inmuebles que reciban un beneficio, y que los recursos están destinados a cumplir fines loables en lo social, y claramente redistributivos, sin excepción tendremos que concluir que la financiación del desarrollo urbano con este tributo pertenece a la categoría de gastos públicos progresivos y redistributivos. En sentido contrario, en este aspecto la contribución de valorización, si bien puede afirmarse que es progresiva, no es redistributiva en cuanto los recursos obtenidos por las administraciones están destinados al mismo grupo social.

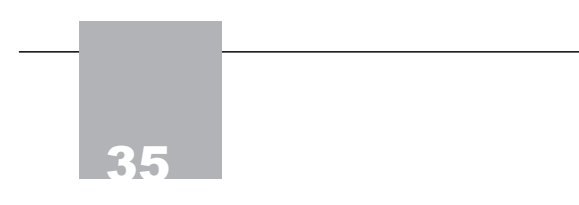

25. Dino Jarach. "Los gastos públicos", en Finanzas públicas y derecho tributario, 2. ${ }^{\text {a }}$ ed., Buenos Aires, Abeledo-Perrot, p. 224. 